\title{
MODEL CNN LENET DALAM PENGENALAN JENIS GOLONGAN KENDARAAN PADA JALAN TOL
}

\author{
Anggay Luri Pramana ${ }^{1}$, Endang Setyati ${ }^{2}$, Yosi Kristian ${ }^{3}$ \\ 1,2,3 Program Studi Teknologi Informasi, Fakultas Sains, Institut Sains dan Teknologi Terpadu Surabaya \\ Jl. Ngagel Jaya Tengah 73-77, Surabaya, Indonesia 6028 \\ Tel. +62 315027920 Fax. +62 31504 1509, +62 315031818 \\ E-Mail : ${ }^{1}$ anggaluripramana@gmail.com, ${ }^{2}$ endan@stts.edu, ${ }^{3}$ yosi@stts.edu
}

\begin{abstract}
Research in the field of transportation, especially vehicle classification with various methods, is a widely developed field of study. Vehicles can be categorized by shape, dimension, logo, and type. The vehicle dataset is also not difficult to find because it is general in nature. Based on the research that has been done, the introduction of group types based on the number of axles with CNN, the dataset is not yet available to the public. In this paper, we discuss the introduction of the types of groups using the Convolutional Neural Network method. The architecture used is the LeNet model. The trial scenario is carried out in 4 stages, namely 25 epochs, 50 epochs, 75 epochs and 100 epochs. Based on the test results, the accuracy obtained continues to increase at 50 epochs and 100 epochs iterations. Starting from an accuracy of $82 \%$, 94\% to the highest accuracy of $95 \%$. Likewise in the prediction the data has increased from $80 \%$, 85\% to the highest accuracy that can be $86 \%$. From 50 epochs to 75 epochs, the accuracy of both training and testing has decreased.
\end{abstract}

\section{Keywords: CNN, LeNet, Relu Activation, Transportation System, Vehicle Type Classification}

\section{Pendahuluan}

Transportasi adalah perpindahan manusia atau barang dari satu tempat ke tempat lainnya dengan menggunakan sebuah kendaraan yang digerakkan oleh manusia atau mesin Transportasi digunakan untuk memudahkan manusia dalam melakukan aktivitas sehari-hari. Transportasi sendiri dibagi menjadi 3 yaitu, Darat, Udara dan Air.

Transportasi di Indonesia pada sektor darat memilki jenis golongan kendaraan khususnya di jalan tol. berdasarkan informasi yang dikutip dari situs Kementrian Pekerjaan Umum dan Perumahan Rakyat, http://bpjt.pu.go.id/konten/golongan-kendaraan. jenis golongan kendaraan dibagi menjadi 5 golongan yaitu golongan 1 hingga golongan 5.

Pada era technology saat ini, banyak sekali inovasi dibidang teknologi yang dikembangakan pada bidang sistem transportasi. Klasifikasi kendaraan menggunakan pengolahan citra dan computer vision memberikan kemudahan terhadap bidang transaportasi. Kemudahan dirasakan pada jalan yang padat sehingga dapat menghitung kendaraan yang keluar dan masuk (Zheng J, Wang Y, and Zeng W, 2015).

IEEE Intelligent Vehicles Symposium adalah forum teknis tahunan utamayang disponsori oleh IEEE Intelligent Transportation System Society (ITSS), yang menyatukan para peneliti dan praktisi di seluruh dunia untuk berbagi kemajuan terbaru dalam teori dan teknologi yang tekait dengan kendaraan cerdas. pada 2017 penelitian dilakukan dengan metode CNN untuk klasifikasi kendaraan (Chen Y, Zhu W, Yao D, and Zhang L, 2017), dan klasifikasi kendaraan juga dilakukan dengan metode $\mathrm{CNN}$ (Huang C, Liang B, Li W, and Han S, 2017).
Convolutional Neural Network (CNN) sebuah metode yang digunakan untuk data yang berupa image, CNN dapat digunakan untuk mendeteksi dan mengenali objek gambar. Arsitektur Neural Network memiliki kemampuan jaringan multilayer dengan gradient descent untuk mempelajari pemetaan nonlinier yang kompleks dan berdimensi tinggi (Callet P L, Viard-Gaudin C, and Barba D, 2006). CNN memliki neuron yang memiliki bobot, bias dan fungsi aktifasi. Secara garis besar didalam CNN memiliki dua tahap yaitu : Feature Learning dan Classification.

\section{Metode}

Untuk memudahkan penelitian ini kami melakukan 2 proses agar didapatkan hasil prediksi jenis golongan kendaraan. Yang pertama adalah preprocessing yaitu proses deteksi object kendaraan yang selanjutnya akan digunakan sebagai proses training dan testing. Yang kedua yaitu proses training dan testing dataset menggunakan Convolutional Neural Network. Untuk proses lengkapnya dijelaskan di setiap subbabnya.

\subsection{Daftar Kelas}

Dataset yang digunakan berupa foto yang diambil dari gerbang jalan tol. Object di ambil dengan kamera handphone. Object di ambil pada waktu pagi hari pukul 09.00 hingga siang hari pukul 11.00. total dataset yang digunakan berjumlah 500. Setiap golongan 1-5 masingmasing diambil 100. Contoh kendaraan yang sudah setiap golongan dapat dilihat pada Tabel 1 ini. 
Tabel 1. Daftar Kelas Golongan 1-5

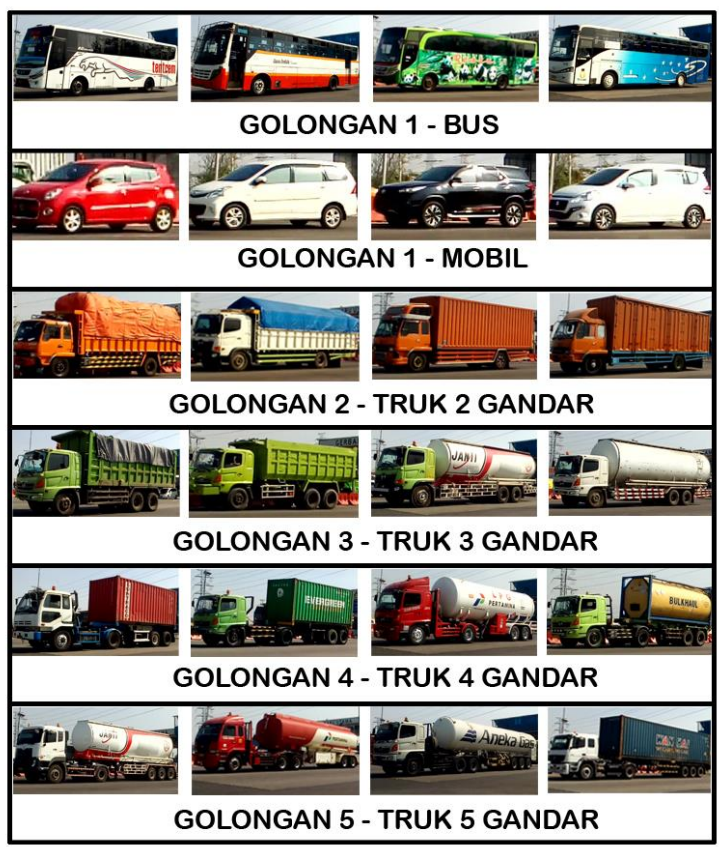

\subsection{Preprocessing}

Tahap preprocessing dilakukan untuk mendapatkan object kendaraan agar mempermudah pada saat training CNN. Tahapan deteksi dilakukan antara lain deteksi kendaraan, cropping, dan merubah gambar ke dalam 1 channel warna grayscale. Alur preprocessing dapat dilihat pada Gambar 1.

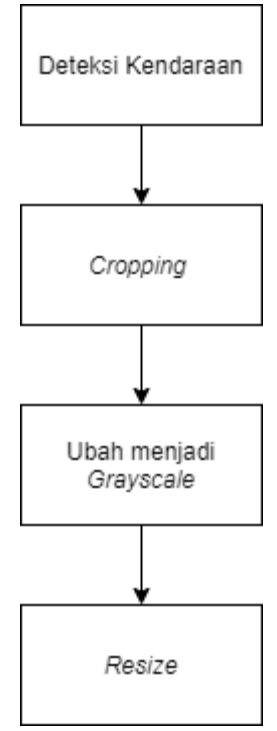

Gambar 1. Tahap Preprocessing

Langkah pertama yang dilakukan yaitu deteksi kendaraan. Deteksi kendaraan menggunakan algoritma YoLo (Melek C G, Sonmez E B, and Albayrak S, 2019). Setelah diperoleh object kendaraan langkah berikutnya yaitu cropping gambar dan setelah gambar di cropping lalu di resize menjadi 100x100 pixel. Tujuan gambar di ubah menjadi grayscale untuk mempermudah proses pada Convolutional Neural Network dan gambar di resize untuk mempercepat proses training dataset pada Convolutional Neural Network. hasil grayscale dan resize dapat dilihat pada Tabel 2 .

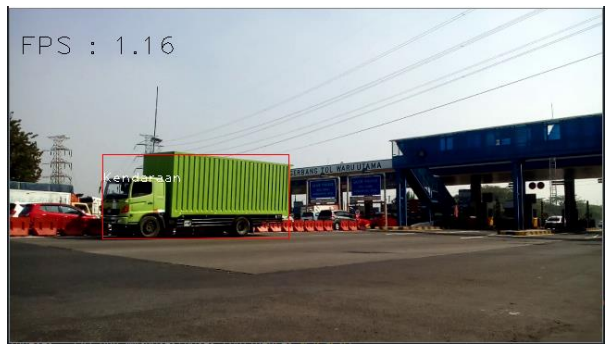

Gambar 2. Deteksi Kendaraan

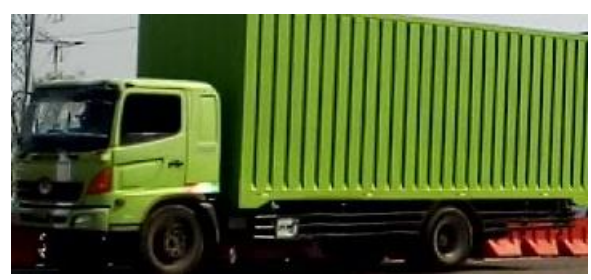

Gambar 3. Cropping Gambar Kendaraan

Tabel 2. Hasil Preprocessing

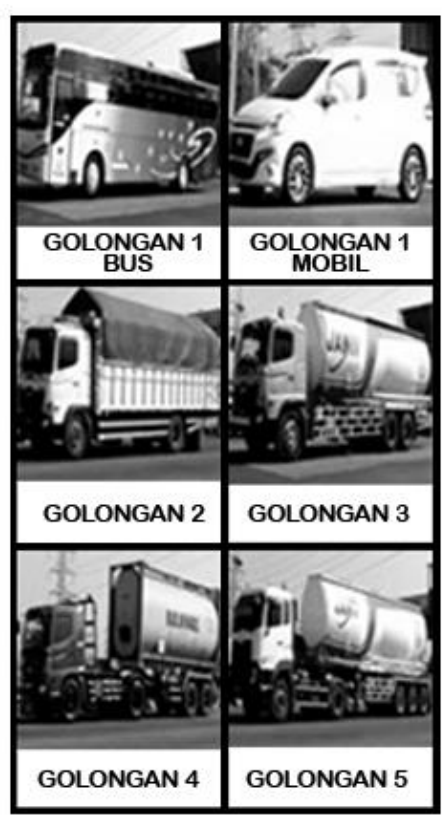

2.3 Arsitektur Convolutional Neural Network

Penelitian ini menggunakan model LeNet. LeNet dipilih karena pada penelitian (Bakti M B S and Melita Pranoto Y M, 2019) mendapatkan 98,89\% dan pada penelitian (Septianto T dkk, 2018) mendapatkan 85,08\% untuk klasifikasi object gambar. Pada gambar 4 menunjukkan arsitekstur CNN yang diajukan. Ukuran input yaitu 100x100x1 dan gambar memliki satu channel yaitu grayscale. Layer konvolusi pertama meggunakan kernel 3x3 sebanyak 32. Layer konvolusi kedua menggunakan kernel 3x3 sebnayak 64. Seteleah di konvolusi dilanjutkan dengan Max Pooling ukuran 2x2. Setelah dicari nilai tertinggi menggunakan Max 
Pooling dilanjutkan dengan melakukan Dropout langkah ini dilakukan agar dataset yang di traiing tidak mengalami overfitting. Proses terakhir yaitu Fully Connected sebanyak 5, karena output yang digunakan sebanyak 5 kelas.

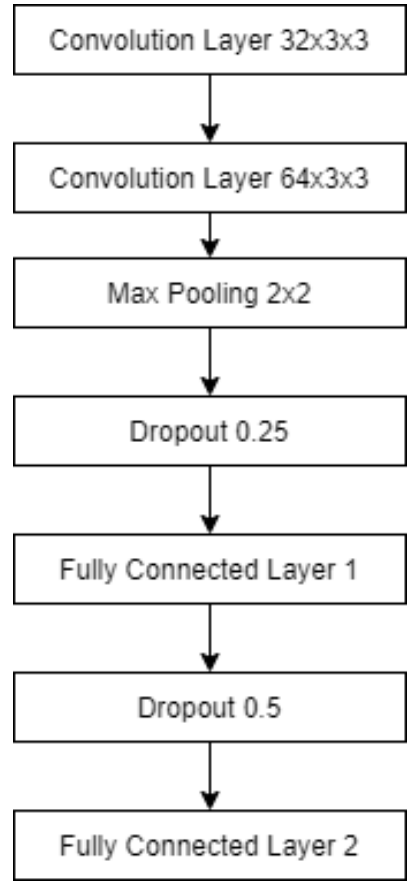

\section{Gambar 4. Arsitektur CNN LeNet}

Pada setiap layar konvolusi terdapat hidden layer dan activation function ReLu. Fungsi aktifasi ReLu dapat juga mengurangi overfitting yang terjadi. Pada rumus 1 dijelaskan tentang fungsi ReLu.

$\mathrm{f}(\mathrm{x})=\max (0, \max )$ 1

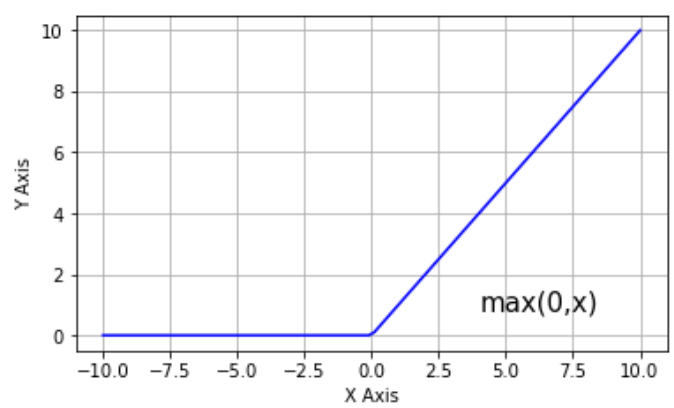

Gambar 5. ReLu Activation

Pooling Layer memiliki filter $2 \times 2$ dan filter ini akan bergeser kesetiap element pixel dari feature map. Max Pooling digunakan dalam penelitian ini untuk mengamnbil nilai tertinggi dari element pixel yang dilewati. Max Pooling digunakan dengan tujuan untuk mengurangi dimensi gambar sehingga proses training lebih cepat dan mengurangi overfitting. Cara kerja Max Pooling dapat dilihat pada gambar 6. Konfigurasi nilai dropout adalah 0.25 sebelum $F C$ layer pertama dan 0.5 untuk FC layer kedua. Algoritma yang digunakan adalah ADADELTA (Zeiller M D, 2012)
Setelah dilakukan proses training, hasil akan didapatkan. Hasil training akan menunjukkan nilai loss dari training dataset. Serta dalam proses training akan didapatkan nilai bobot berupa weight model. Nilai bobot akan dimuat kedalam proses testing hingga dapat memperoleh hasil prediksi data.

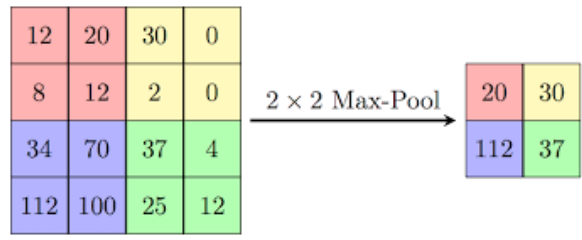

Gambar 6. Max Pooling

3. HASIL DAN PEMBAHASAN

Proses training dilakukan menggunakan Laptop core i5, RAM 12 GB. Training dan testing di proses menggunakan CPU. Training dan tesing dataset menggunakan editor python. Library dan Framework yang digunakan yaitu keras dengan tensorflow sebagai backend.

Dataset yang digunakan dibagi menjadi 2 bagian sebelum training dilakukan, yaitu dataset training dan dataset testing untuk prediksi jenis golongan. Dataset sebanyak 500 dibagi menjadi $80 \%$ sebagai training dan $20 \%$ sebagai testing. Proses training dan testing dilakukan dalam 3 tahap, tahap pertama dilakukan training dengan 25 epochs tahap selanjutnya 50 epochs, 75 epochs dan 100 epochs. Scenario tersebut dilakukan dengan tujuan agar didapat nilai akurasi yang didapat di setiap epochs.

Ujicoba pertama dilakukan training 25 epochs. Hasilnya nilai akurasi yang didapat adalah $82 \%$ denga nilai loss $43 \%$. Hasil akurasi yang didapat dirasa belum maksimal. Langkah selanjutnya yaitu dilakukan prediksi terhadap $20 \%$ data testing. Hasil dari prediksi yang dilakukan mendapat akurasi sebesar $80 \%$, dari total data prediksi. Dari 100 data prediksi, 20 data yang mendapat kesalahan prediksi. Dari 5 kelas yang ada, golongan 2 dan golongan 3 yang dapat dikenali $100 \%$.

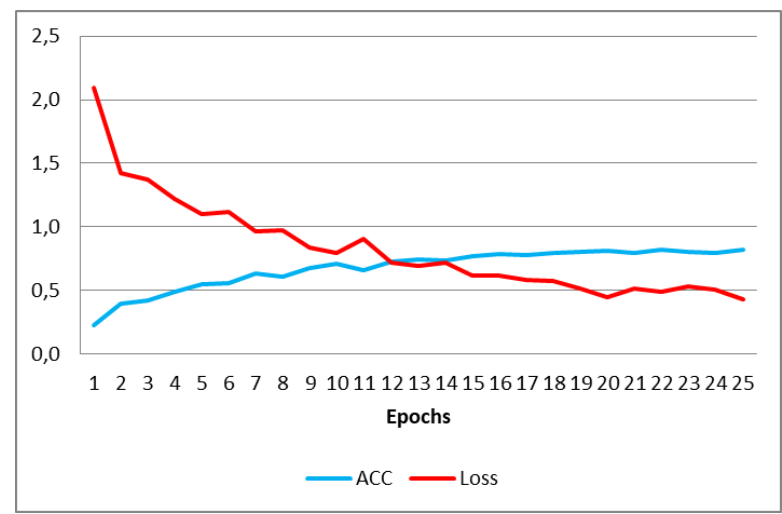

Gambar 6. Nilai Akurasi dan Loss 25 Epochs

Ujicoba kedua dilakukan training dengan jumlah dataset yang sama yaitu 500 dataset. Training dilakukan dengan iterasi 50 epochs. Hasil yang didapat pada ujicoba tahap dua nilai akurasinya meningkat dari 
ujicoba tahap pertama dengan nilai akurasi 93\% dan nilai loss yang menurun yaitu $18 \%$. Setelah itu dilanjutkan proses prediksi pada data testing dan hasil prediksi meningkat pada angka $85 \%$. Dari total 100 data prediksi, 15 data gambar yang mendapat kesalahan prediksi. Di ujicoba tahap kedua nilai loss menurun dari 19 menjadi 15 , serta golongan 1 dan 3 adalah kelas yang dapat di prediksi $100 \%$.

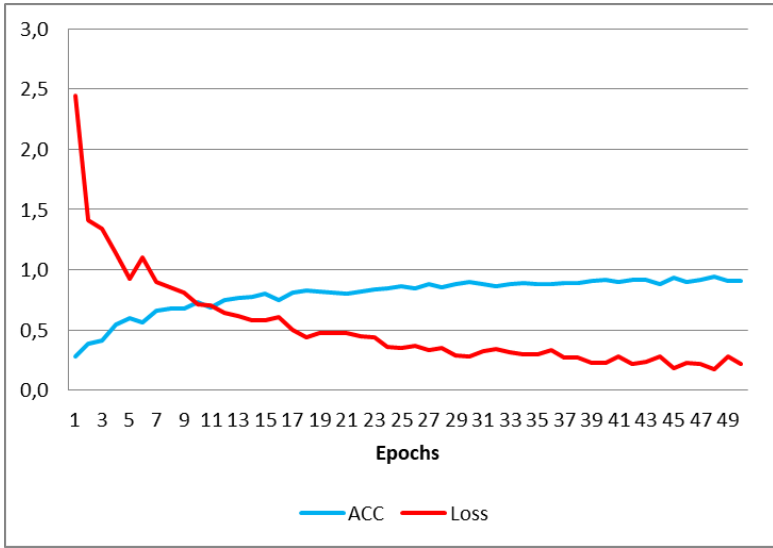

Gambar 7. Nilai Akurasi dan Loss 50 Epochs

Ujicoba ketiga dilakukan dengan jumlah dataset 500 . Training dilakukan dengan iterasi 75 epochs. Hasil yang didapat pada ujicoba ketiga nilai akurasinya menurun dari ujicoba kedua sebesar $93 \%$ dan nilai loss meniingkat menjadi $18 \%$. Proses dilanjutkan dengan prediksi data testing, dan hasil prediksi menurun menjadi $79 \%$. Dari total 100 data prediksi, kesalahan prediksi gambar juga meningkat menjadi 21 dari total gambar 100. Dan golongan 1 adalah kelas yang mendapat prediksi $100 \%$.

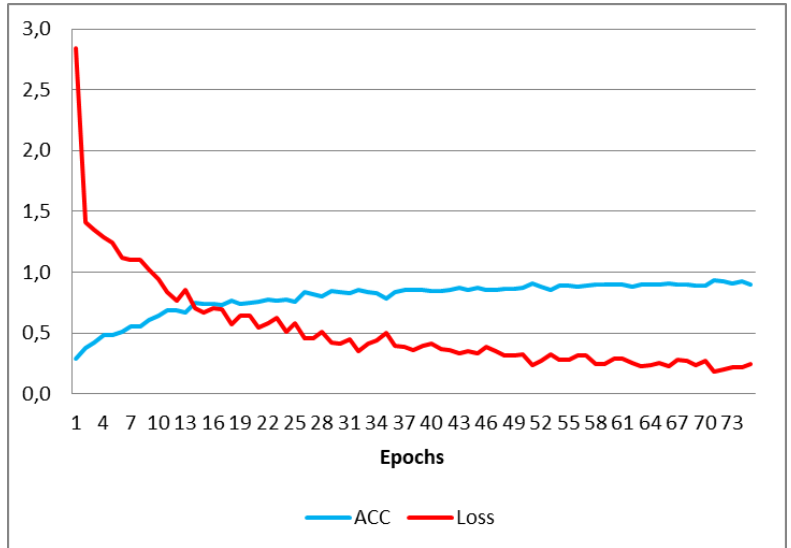

Gambar 8. Nilai Akurasi dan Loss 75 Epochs

Ujicoba keempat dilakukan dengan jumlah dataset 500. Training dalam ujicoba keempat ini dilakukan dengan iterasi 100 epochs. Hasil yang didapatkan pada ujicoba keempat adalah nilai akurasinya naik dari ujicoba ketiga sebesar $93 \%$ di ujicoba keempat menjadi $95 \%$ dan nilai loss menurun hingga $10 \%$. Hasil ujicoba keempat ini mendapat akurasi yang paling tinggi dari ketiga ujicoba yang dilakukan. Untuk prediksi golongan dari 100 data 14 yang mendapat kesalahan dalam prediksi. Hasil prediksi di ujicoba keempat mendapat hasil paling tinggi dari ketiga ujicoba yang dilakukan. Di ujicoba keempat golongan 2 dan 3 mendapat prediksi $100 \%$.

Untuk data lebih detail dari proses prediksi dapat dilihat pada tabel 2 .

Tabel 2. Hasil Prediksi Data

\begin{tabular}{|c|c|c|c|c|c|c|}
\hline \multicolumn{2}{|c|}{ Kelas } & $\begin{array}{c}\text { Golongan } \\
1\end{array}$ & $\begin{array}{c}\text { Golongan } \\
2\end{array}$ & $\begin{array}{c}\text { Golongan } \\
3\end{array}$ & $\begin{array}{c}\text { Golongan } \\
4\end{array}$ & $\begin{array}{c}\text { Golongan } \\
5\end{array}$ \\
\hline \multirow{2}{*}{25 Epochs } & $\begin{array}{c}\text { Akurasi } \\
(\%)\end{array}$ & 100 & 60 & 100 & 80 & 60 \\
\hline & Error & - & $\begin{array}{c}3,3,4,3,3,1,1 \\
4 \\
\end{array}$ & - & $5,5,3,3$ & $\begin{array}{c}4,4,4,3,4,4,4 \\
4 \\
\end{array}$ \\
\hline \multirow{2}{*}{50 Epochs } & $\begin{array}{c}\text { Akurasi } \\
(\%)\end{array}$ & 100 & 75 & 100 & 90 & 60 \\
\hline & Error & - & $3,3,3,3,4$ & - & 5,3 & $\begin{array}{c}4,4,4,4,4,4,4 \\
, 4 \\
\end{array}$ \\
\hline \multirow{2}{*}{75 Epochs } & $\begin{array}{c}\text { Akurasi } \\
(\%)\end{array}$ & 100 & 55 & 95 & 80 & 65 \\
\hline & Error & - & $\begin{array}{c}3,3,3,3,1,1,1 \\
, 1,1 \\
\end{array}$ & 1 & $2,5,5,3$ & $4,4,4,4,4,4,4$ \\
\hline \multirow{2}{*}{100 Epochs } & $\begin{array}{c}\text { Akurasi } \\
(\%)\end{array}$ & 100 & 75 & 100 & 95 & 60 \\
\hline & Error & - & $3,3,3,3,3$ & - & 3 & $\begin{array}{c}4,4,4,4,4,4,4 \\
, 3\end{array}$ \\
\hline
\end{tabular}

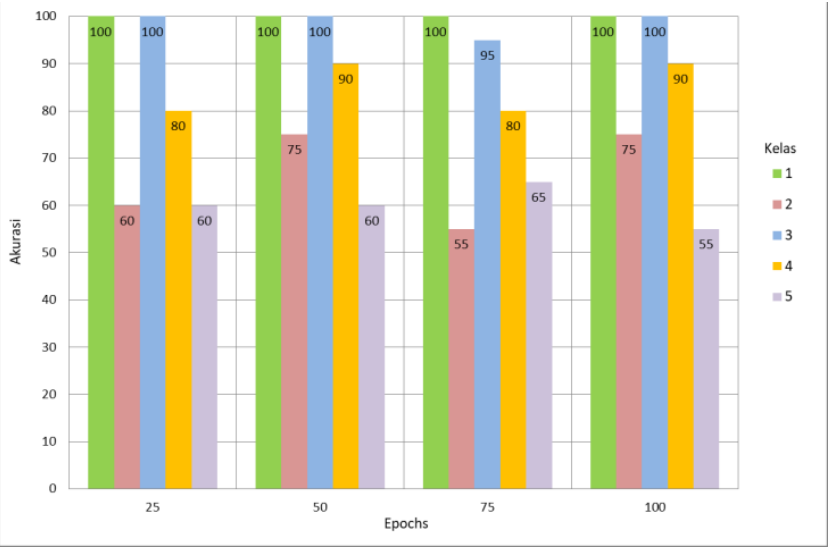

Gambar 9. Akurasi Prediksi Setiap Kelas

\section{KESIMPULAN}

Pada era digital saat ini banyak media digunakan sebagai pengembangan transportasi, sebagai contoh sistem deteksi kendaraan yang bermanfaat untuk menghitung banyaknya kendaraan yang melewati jalan tersebut. Machine Learning adalah salah satu dari perkembangan teknologi yang popular, dan Convolutional Neural Network menjadi metode yang banyak digunakan dalam berbagai penelitian dan juga menjadi metode yang dapat mengatasi permasalahan transportasi dengan hasil akurasi yang cukup baik.

Arsitektur CNN biasa dimodifikasi sesuai dengan kebutuhan. Model LeNet adalah adalah satu dari sekian metode CNN yang sesuai untuk pemrosesan citra digital. Dari hasil ujicoba yang dilakukan menggunakan model LeNet terbukti mendapat akurasi training dan testing hingga $95 \%$. pada proses training setiap iterasi epochs dapat mempengaruhi nilai akurasi. Hal tersebut dapat dibuktikan dari 25 sampai 100 epochs dimana 
nilai akurasi terus meningkat hingga $95 \%$ dengan nilai loss $10 \%$.

Pada penelitian ini tentu masih banyak memiliki kekurangan. Kedepan akan perlu perbaikan dalam penelitian selanjutnya. Ada harapan agar sistem transportasi diindonesia dapat ditunjang dari segi teknologi. Untuk mengurangi masalah-masalah yang sedang terjadi khususnya dijalan raya. Maka dari itu akan banyak penelitian dalam bidang transportasi yg dilakukan menggunakan machine learning.

\section{PUSTAKA}

Jilong Zheng, Yaowei Wang, and Wei Zeng, "CNN Based Vehicle Counting with Virtual Coil in Traffic Surveillance Video" 2015 IEEE International Conference on Multimedia Big Data, pp. 280-281, 2015, doi: 10.1109/BigMM.2015.56.

Yanjun Chen, Wenxing Zhu, Donghui Yao, and Lidong Zhang, "Vehicle Type Classification based on Convolutional Neural Network", Shandong University, Jinan China, pp. 1898-1901, 2017, doi : 10.1109/CAC.2017.8243078.

Changxin Huang, Binbin Liang, Wei Li, and Songchen Han, "A Convolutional Neural Network Architecture for Vehicle Logo Recognition", 978-1-5386-31072/17/\$31. 00@2017 IEEE, pp. 282-287, doi: 10.1109/ICUS.2017.8278355.

Patrick Le Callet, Christian Viard-Gaudin, and Dominique Barba, "A Convolutional Neural Network Approach for Objective Video Quality Assessment", member IEEE, 1045-9227, 2006, IEEE., doi: 10.1109/TNN.2006.879766.

Ceren Gulra Melek, Elena Battini Sonmez, and Songul Albayrak, "Object Detection in Shelf Images with YOLO” 978-1-5386-9301-8/19/\$31.00 (C2019 IEEE, 2019, doi: 10.1109/EUROCON.2019.8861817.

Mochamad Bagus Setiyo Bakti, and Yuliana Melita Pranoto, "Pengenalan Angka Sistem Isyarat Bahasa Indonesia Dengan Menggunakan Metode Convolutional Neural Network" Seminar Nasional Inovasi Teknologi UN PGRI Kediri 2019, pp. 11-16, 2019.

Septianto T, Setyati E dan Santoso J, "Model CNN LeNet dalam Rekognisi Angka Tahun pada Prasasti Peninggalan Kerajaan Majapahit" Jurnal Teknologi dan Sistem Komputer Jilid 6 Terbitan 3, pp. 106109, 2018.

Mattew D. Zeiller " Adadelta : An Adaptive Learning Rate Mehod" Cornell University, 2012. 